\title{
3 Cultivating ethical negotiations or fetishising consent in BDSM?
}

\author{
Monika Grønli Rosten
}

\section{Introduction}

By the end of 2015, I had begun to recruit participants for a research project on exposure to intimate partner violence (IPV) and help-seeking as part of the domestic-violence research programme (2014-2019) at the Norwegian Centre for Violence and Traumatic Stress Studies. One day I received an email from Tina (26):

I think I might be in the target group for your study, but I'm struggling to explain why. A few years ago, I was in a relationship with a woman, and I've realised since then that I've been manipulated, forced into situations where I was uncomfortable, and it feels like I've lost myself somehow along the way. She performed a kind of 'voluntary' violence against me, as we both consented to it (BDSM). Since the relationship ended, I've struggled with severe anxiety and depression, and I haven't been able to seek help.

Tina had engaged in an intimate relationship involving the practice of BDSM (bondage/discipline, dominance/submission, sadism/masochism). As an acronym for bondage/discipline, dominance/submission and sadism/masochism, the term 'BDSM' is used to distinguish a wide range of erotic practices from mainstream normative sexuality. BDSM community members often juxtapose their own various alternative practices with the duller 'vanilla sex' practised by outsiders (Newmahr, 2011).

When the relationship ended, Tina found herself hurt, confused and frightened. In her own words, she had been exposed to violence 'kind of voluntarily' (i.e. BDSM), which made her wonder whether she was in the target group for a study on IPV. Had she been subjected to physical or sexual violence at all? Had she instead experienced psychological abuse from a manipulative girlfriend? Or could what happened between them simply be labelled 'bad BDSM', in the popular sense of 'bad sex'? She asked herself these questions as she deliberated whether she was entitled to professional help for a 'self-inflicted' trauma.

This chapter, using the complex relationship between sexuality and power exchanges in BDSM as a backdrop, will address what has been referred to as 
the 'grey area' (Gavey, 2005) and the 'murky interface of consent and coercion' (Gunnarsson, 2018, p. 3). The World Health Organization (WHO, 2002) defines violence as 'the intentional use of physical force or power, threatened or actual, against oneself, another person, or against a group or community, that either results in or has a high likelihood of resulting in injury, death, psychological harm, maldevelopment or deprivation'. In this definition, violence is understood as an actual fact: both an intention and a set of real-life consequences. In the following analysis, we will instead understand violence as a social construct that emerges from struggles of legitimacy in a particular cultural and historical context.

In this chapter, I refer to illegitimate BDSM as 'sexual violence', as BDSM in my understanding is strongly related but at the same time encompasses sexuality. What differentiates BDSM from sexual violence, as a socially constructed category, is first the prerequisite of consent (or not) to participate, and second the fact that the BDSM practice itself is seen as a game of make-believe, as opposed to real violence (McClintock, 1993; Newmahr, 2010). But how do participants in BDSM draw this line in actual practice, and what role does the idea of consent play?

Throughout this chapter, we will explore the social construction of sexual violence in BDSM from different angles, all revolving around the question of consent. I will problematise the idea of consent as a way of properly distinguishing BDSM from sexual violence by drawing on interviews with Tina and other BDSM practitioners. Towards the end of the chapter, I will reflect on what we can learn about IPV and consent from this particular context.

\section{The consent problem}

The concept of consent tends to mean different things to different people, both in academic discourse and in everyday life. In relation to sexuality, 'consent' can be defined as the 'the freely given verbal or non-verbal communication of a feeling of willingness' (Hickman \& Muehlenhard, 1999, p. 259). In sexual-violence prevention in the Western world, according to Beres (2014, p. 373), the message "no means no' has gradually been replaced by 'yes means yes'. The same discursive shift is visible in online BDSM communities and the blogosphere (Barker, 2013). Encouraging explicit rather than implicit communication of consent is often seen as a way of avoiding misunderstandings.

Insisting on the importance of affirmative consent is also useful in fighting sexual violence. Rape is wrong, Cahill states (2001, p. 170), precisely because 'it undermines the integrity of the personhood of the victim by denying their right of consent over that property that is most personally, most intensely held: the body'. In Cahill's discussion of rape and the problem of consent (2001), the author further explains how rape in the traditional Western understanding was defined as a crime against primarily male property. In this logic, women did not possess their sexuality, so the question of consent was irrelevant. In liberal theory, in contrast, rape is a violation of personal autonomy, where lack of consent is the very definition of the crime. An obvious challenge in this approach is that the communication of consent is not necessarily the same as actually 
wanting to participate (Beres, 2014; West, 2008). In the classic 'Women and Consent', Pateman defines the consent problem as an ideal in liberal societies: 'consent is central to liberal democracy, because it is essential to maintain individual freedom and equality; but it is a problem for liberal democracy, because individual freedom and equality is also a precondition for the practice of consent' (1980, p. 162). In other words, consent is never given in a social vacuum and therefore should be discussed with reference to the ethical negotiations related to consent, since it occurs within a social context of unequally distributed opportunity for freedom and equality.

The following problematisation of consent as negotiated within the subcultural social context of BDSM is inspired by Pateman's (1980, p. 162) insistence on taking into account these 'realities of power and domination in sexual and political lives'. Ethnographic studies of sadomasochism (SM) have problematised the limits of conceptualising the individual by demonstrating how ritual practices within such communities seem to be articulated precisely in the language of individualism (Martin, 2011). The act of consent/non-consent is often seen as an individual responsibility. Against this modern conception of an essential self stands the postmodern deconstruction of the individual subject. Using a Foucauldian understanding, ethical work on the self as part of the governing of souls in modern societies ('governmentality') involves both caring for the self and for others (Foucault, 2003, 2009). Foucault defines this self-formation of the ethical subject as a constant process of acting, monitoring and transforming oneself in relation to particular moral goals and ideals (Foucault, 2001, 1985 [2014]). Carmody (2003, p. 201) builds on Foucault's work when arguing for a discourse on sexual-violence prevention that would acknowledge precisely the ability to ethically negotiate and to establish an 'erotics of consent' across gender and power differences.

\section{Method}

The work in this chapter resembles the process of 'abduction', which Timmermans and Tavory (2012, p. 169) describe as 'the cultivation of anomalous and surprising empirical findings'. As a researcher of IPV with little knowledge of the practice of BDSM, I welcomed the opportunity Tina offered to be led astray, since I hoped to be able to develop novel theoretical insights from her story. In order to understand Tina's attempts to carve out the sexual violence from the BDSM context in her story, I had to expand my initial research project on IPV. Via colleagues and friends, I managed to be introduced to people with an interest in BDSM; through their network, I then recruited seven informants for interviews, in addition to Tina.

These informants were experienced in practising BDSM with life-partners or play partners, and they all had overlapping social networks within local, national and even international BDSM communities. Since the number of interviews had to be limited, I tried to recruit male and female informants with different role preferences in order to analytically explore issues of power exchange from different angles; these roles included 'dominant', 'submissive' (or 'sub') and 'switch', 
a subcultural term for those who sometimes like to dominate and sometimes prefer the role of sub. All informants identified themselves as heterosexual; I found this analytically fruitful, as Tina herself was clear that her story was about abuse in a BDSM relationship, rather than abuse in an LGBTQ relationship. Unlike Tina, the other informants had higher education. Several had academic or even political interest in BDSM: they had read extensively on the subject and had engaged in activism and identity politics to create a more tolerant and 'kink-friendly' society.

I conducted three additional individual interviews with two women (Linda and Mari) and one man (Lukas), all in their 30s. These were qualitative semistructured interviews lasting about two hours, where the informants were asked to describe their personal practice and to explain the role BDSM played in their social lives and as part of their identities. They were also invited, throughout the interview, to reflect on how to draw the line between BDSM and abuse. In addition, three men and one woman (ages 25-40) were interviewed in a group, as friends and fellow members of a BDSM club. Before the group interview, the four participants were asked to read an anonymised short version of Tina's story. In the interview, the story could then serve as a starting point for discussions about how BDSM and sexual violence can be separated. During the interview, I tried to remain passive and not offer my point of view; instead, I listened to their discussions.

The individual interviews were transcribed and analysed. After the group interview, the field notes from the session (and later, an early draft of the chapter) were shared with and commented on by the participants in order to avoid misunderstandings and misinterpretations on my part. I also conducted a follow-up interview with Tina about a year after the first one to get her opinion about my interpretation and analysis of her story. The informants insisted on the importance of their preferred positions (dominant, sub or switch) as well as their gender and sexuality (homo/hetero) for their perspectives on BDSM and sexual violence. At the same time, I was fascinated by the similarities in perspective across such dividing lines as I carved out a shared understanding of the difference between BDSM and sexual violence in the analysis. I understand these similarities from different standpoints as being indicative of high-level social/cultural integration in the larger BDSM community.

In addition to conducting interviews, I observed the participants at BDSMrelated events, such as public lectures during the 2017 Oslo Pride festival, where I engaged in more informal conversations with practitioners. I also searched Norwegian and international BDSM community websites for relevant information on the phenomenon of sexual violence in the BDSM context.

Anonymity is crucial in this project, as the informants most often kept their BDSM practice secret at work or with certain friends and family members. I discussed the issue of anonymity with each interviewee. In addition to using pseudonyms, I have changed several details in their personal stories and quotations. The following includes an analysis of what BDSM essentially is before discussing (through the analysis of Tina's story) what separates BDSM from sexual violence. 


\section{BDSM as perversion, alternative sexuality or lifestyle}

Outsiders often understand BDSM to be either an alternative sexual practice or a form of role-play between consenting adults who suspend their individual lived realities for the sake of erotic enjoyment (Newmahr, 2010). In Foucault's The History of Sexuality (1984), the author describes how sexuality throughout history has become a domain of regulation and social control. According to Foucault, this transformation of sex into discourse endeavours 'to expel from reality the forms of sexuality that were not amenable to the strict economy of reproduction' (1984, p. 36). In a Foucauldian understanding, the 'perversions' included in the BDSM category are products of society's efforts to suppress them. These practices are included in socially constructed hierarchies of sexual value, where some forms of sexuality are valued as 'good', 'normal' and 'natural', whereas others are singled out as 'bad', 'abnormal' and 'unnatural' (Rubin, 1984, pp. 280-281).

In an interview about sex, power and the politics of identity, Foucault discusses sadomasochism (SM) as an attempt to 'de-sexualise pleasure' in a society where traditional understandings of physical pleasure seem limited to eating, drinking and sex (2001, p. 1557). In Foucault's analysis, SM is neither simply a form of alternative sexuality nor a way of releasing suppressed aggression and violence (2001) but rather an alternative way of seeking pleasure. This view seems to agree with the general understanding expressed by the BDSM practitioners I interviewed. A woman I met at a BDSM lecture referred to herself as a 'sadist' in the BDSM context. She told me that over the years, she had concluded that sex for her was about penetration or the touching of genitals. Whether or not sex is included in BDSM play thus depends on the practice, in her understanding. As she explained, 'I actually stopped having sex with my boyfriend many years ago, but I love playing with him'.

There is a growing body of literature on sadomasochism and fetishism in the social sciences that I will not be able to engage with here; see Weinberg (2006) for an extensive review. Practices now often referred to as BDSM have become more visible in the mainstream since the Fifty Shades series (Deller, Harman \& Jones, 2013) and thus more accepted as a way of 'spicing up' one's sex life. Still, from my informants' points of view, BDSM is not reducible to the practice of 'kinky sex'. One of them, Linda, has been part of a BDSM community since she was a teenager and characterises her fellow 'BDSMers' as 'a bunch of friendly geeks'. Linda practices BDSM both in private with her husband and with playing partners at the local club. She identifies herself as switch. 'Please don't get me started on the Fifty Shades hype', she says, implying that her community's BDSM is something else. For Linda, BDSM is a crucial part of her identity as well as an interest she has in common with most of her 'geek' friends and thus not simply a 'practice' or a 'sexual/relational orientation'. Linda's description resonates with Newmahr's findings from an ethnographic study of a US-based SM community that it is: 'an all-encompassing lifestyle that represents liberation from the oppressive plight of the everyman and nurtures identities of marginality' (2011, p. 9). 
From an outsider's perspective, BDSM practices might appear as obeying conventions of power (such as the largely gendered patterns of male dominance and female submission) and perhaps even violence, such as the acceptance of physical pain and bloodshed. The difference lies in the meanings the participants apply (Carlström, 2018). Based on her studies of commercial fetishism and gender power, McClintock (1993, p. 89) argues that despite its apparent servility to traditional power, SM 'performs social power as scripted, and hence as permanently subject to change'. But this opening for change is often understated when insiders draw the line between play and abuse, as if this boundary were fixed and non-negotiable (Wiseman, 1996). People often explicitly refer to the commonly accepted ground rules that BDSM practice should always be 'safe, sane and consensual', or SSC.

\section{SSC and ethical BDSM}

David Stein first introduced the SSC ground rules at an SM-community conference in Washington, DC, in 2000; they have since become a litmus test for 'proper' BDSM. Newmahr (2011, p. 147) expands on this point in her ethnographical studies of SM practices: "“safe, sane and consensual" is what makes SM morally acceptable. The concept thus has come to constitute SM; what is not safe and sane and consensual is not SM, and therefore does not belong in the community'. SSC works as a conceptual tool for acceptance and understanding outside the communities, as well as a way of protecting oneself and each other on the inside. Practitioners consider consent to be crucial. As Newmahr (2011, p. 149) states,

the most serious of the boundaries with which to play, from the perspective of the community, is not the line between life and death, but the edge between consent and non-consent. In the consciousness of the community, deference for a sharply drawn line here separates SM from criminal behavior.

Newmahr's description here illustrates Fanghanels point (2019) that consent in BDSM, the negotiation between risk and trust, must be understood as a practice of community-building, relying on the neoliberal constructions of the autonomous self.

In an interview with Lukas, an experienced sub, he admits that the SSC guidelines do not solve all problems in all situations, but as rules of thumb he finds them 'good to think with'. First, consent to engage in BDSM, according to Lukas, means an enthusiastic expression of free will. In Lukas's understanding, however, the relative health risk in BDSM practice actually implies that consent in itself is not necessarily enough. Accordingly, Lukas defines spanking of the head, stomach, or neck, even if enthusiastically requested, as not safe and therefore not a proper BDSM. He also stresses that BDSM should be practised with a sane mind so that the participants will be able to give their enthusiastic consent. Combining alcohol or drugs with play is not a proper BDSM in his view. In the same logic, Lukas claims that keeping partners socially isolated as part of dominance/submission 
relationships, in a way that hinders them from growing as people, is potentially unhealthy and therefore not a proper BDSM.

Lucas is an idealist and an activist on behalf of his community. The implication of what he says is that ideal BDSM is practised by caring and responsible adults with good social skills and basic knowledge about the human psyche and anatomy. BDSM should be practised with the well-informed intention to please rather than to hurt, within a relational rather than an egotistical logic. Incompetent BDSM playing - or worse, abuse, may be the result when this is not the case. At stake is the boundary between legal, morally acceptable and playful BDSM and illegal, immoral and hurtful sexual violence. Strict, black-and-white dichotomisation between sexual violence and ideal BDSM becomes a way of addressing what outsiders perceive as practices in shades of grey.

Linda, just like Lukas, stresses the importance of belonging to a network of fellow BDSMers so that this clear boundary will not become blurred in practice. When experimenting with technically or psychologically advanced BDSM, people need a place to learn the proper ethics, social rules and language for negotiation and evaluation, and how to take safety precautions and provide proper aftercare. As Linda explains, no matter what role people play (dominant, sub, or switch), they must find what SSC means in their current practice. They must also explore whether their partners' and their own personal boundaries represent 'hard' or 'soft' boundaries: respectively, those that people will not consent to cross at all and those they might cross, from the safe place they have created through negotiations. This distinction between hard and soft boundaries is a way of addressing consent as a question of free will in a floating landscape of explorative pleasure-seeking.

Linda insists on open communication between the parties before, during and after play-sessions, where timing is crucial. When she plays the dominant role with a male sub newcomer at the BDSM club, she never breaks his skin, touches his genitals, or introduces advanced techniques such as breath play without discussing it in advance. An occasion when she has him tied up, hanging upside down, and aroused by the scene is not a good time to ask for permission to touch his genitals. In Linda's understanding, bad timing like this would indeed deprive him of the opportunity to provide consent, in the sense of a conscious expression of free will. She describes how she insists on discussing the details with her playing partners before each session by systematically mapping out each other's hard and soft boundaries, likes and dislikes, and discussing any relevant allergies or other physical conditions. Negotiating BDSM practice at home with her husband is a different situation: they trust each other and can communicate well.

As Carmody argues, much academic discourse on sexual violence has focussed on essentialist ideas about masculinity and femininity, as well as on what is often perceived as 'abnormal' unethical subjects, rather than considering 'how women and men of diverse sexualities do behave as ethical subjects' (2003, p. 211). I see Linda and Lukas as examples of such women and men; in a Foucauldian sense, they seem to include conscious ethical work on the self as part of their BDSM practice. From their point of view, mutual enthusiastic consent is a necessary but insufficient prerequisite for the practice of 'ethical BDSM'. 


\section{Troublesome BDSM}

The tendency among insiders to present BDSM and sexual violence as mutually exclusive is understandable, given the potential social stigma in identifying with BDSM outside of the community. The International Classification of Diseases and Related Health Problems (ICD-11) is a good illustration of existing hierarchies of sexual practices in society (Rubin, 1984). Until June 2018, 'fetishism', 'sadism' and 'masochism' were included in chapter F65 of ICD-11 as forms of 'mental disorders of sexual preference'. According to a revision based on current scientific evidence (Reed et al., 2016, p. 213), these diagnoses were removed, and the new category 'coercive sexual sadism disorder' was introduced 'to clearly distinguish this disorder from consensual sadomasochistic behaviors that do not involve substantial harm or risk'. WHO's recent decision to follow the Nordic countries in removing the diagnoses implies that 'consensual sadomasochism' (or BDSM) will now be considered a sexual practice; 'sexual sadism' aimed at a non-consenting person, in contrast, will still be considered a form of mental disease. The key concept in this distinction between an acceptable sexual preference and a mental disorder is consent.

According to Conly (2004, p. 98), the legal concept of rape traditionally involves two elements: the perpetrator's use of force and the victim's lack of consent. Because use of force is often part of the game in BDSM, mutual consent given by healthy adults has become a major distinction between BDSM (as a legal sexual practice) and illegal sexual violence; see Smart (1995) for a problematisation of earlier jurisprudence in the UK. In a Norwegian court case from 2013 (LH-2012-160658), a man was acquitted for charges of 'grossly negligent sexual assault' in a case where BDSM 'rape play' had resulted in an indictment of rape on the part of a male dominant. The actual play session had been filmed and thus was able to be used as evidence in court. The male dominant/offender asked the female submissive/victim to confirm that she had agreed to be part of a role-play where she was to be raped (including being hit in the face and held down). The woman consented on tape, and during the filmed play session/rape, she screamed 'No', sobbed and asked the man repeatedly to stop. Their mutual agreement beforehand had included the use of a safe word ('red') in case either wanted to end the play session. Because the woman never uttered 'red' on tape, the court could not prove beyond a reasonable doubt either that she had withdrawn her consent or that the man had understood that she wanted him to stop. In other words, the court could not prove that it was dealing with 'non-consensual sexual sadism' rather than 'consensual sadomasochism'; therefore, the male dominant/ offender was free to go.

The international BDSM social movement insists on free mutual consent as the signature of 'healthy BDSM', regardless of gender, class or ethnicity. In actual practice, however, gender is often a crucial factor, as shown in Carlström's studies (2017) among Swedish practitioners who work hard to reconcile gender equality with the power structures of BDSM. As Carlström shows, 
radical feminist theorists tend to see BDSM practices as fundamentally misogynistic products of patriarchy that eroticise power differences of gender, regardless of who dominates whom on the individual level. The BDSM movement, in contrast, is inspired by more 'sex-positive' queer theory, with a different approach to power and consent.

West (2008) makes a point of how both feminist and queer perspectives can be used in obscuring the distinction between consenting and non-consenting sex, pushed to extremes: 'from either perspective, then, consent fades in significance as power looms: for radical feminists, sexual power is coercive with or without consent, and for queer theorists, sexual power is transgressive and pleasure-enhancing, with or without it' $(2009$, p. 19). In sex crime legislation, the concept of consent strictly means giving permission (and thus is under the influence of specific circumstances), whereas a feminist understanding of the concept looks at consent as 'an aspect of relational sexual integrity and autonomy' (Larcombe, Fileborn, Powell, Hanley \& Henry, 2016, p. 614). A common feminist critique of legal definitions of rape has precisely been that these definitions do not always consider the structural inequalities and particular contexts that shape all sexual encounters.

Mari, a woman in her 30s who practises BDSM exclusively in her private home, provided a similar explanation for why she tries to keep her distance from her former BDSM community. To her, the ideals of gender-equal BDSM between consenting adults are not always reflected in actual practice. She uses the example of respect for a stop-word as a way of withdrawing consent: an imperative social norm in BDSM. Mari has experienced how esteemed male dominants get away with breaking this rule because it is up to his female sub to prove that he has indeed disrespected her attempt to stop him. As Mari says:

As a feminist, I find this community problematic, and that's partly why I wish not to be part of it: because so many pretty words are spoken about consent and all that, but in reality, my experience is that these boundaries are fluid. If you go to [a BDSM club] and sit there in the bar, and someone comes up to you and pulls your hair, for instance, then you haven't given your consent. And people say, 'That's just flirting'.

In BDSM, just as in life in general, consent becomes a problematic issue in practice precisely because the consent depends on the particular social context of unequal power relations. BDSM communities often frown upon drawing attention to problematic experiences related to consent. According to Mari, people who speak out against fellow BDSM community members' disrespect of the ideal of mutual and enthusiastic consent tend to experience being 'frozen out' as a result (see also Barker, 2013). There is no reason to believe that feminist attitudes differentiate significantly between sadomasochists and non-sadomasochists (Cross \& Matheson, 2006). That is precisely Mari's point: BDSM takes place within a larger social context characterised by gendered power differences. 


\section{When BDSM becomes violent: Tina's story}

Tina's story is a good example of how the problem of consent encompasses both BDSM ideals and the performative act of giving permission or saying 'yes'. At the age of 23, Tina contacted 'Emma' (10 years older) on Fetlife, the BDSM equivalent of Facebook. Tina was interested in sex rather than something more serious, and Emma was already in a relationship with another woman who accepted her wish to have a playing-partner/girlfriend on the side. During the following year, Tina spent most of her spare time at the couple's house and with their friends, as well as with Emma on her own.

Within the BDSM framework, Tina and her former girlfriend seemed to take their negotiations over practice to ensure mutual consent seriously. Tina explains:

When you're doing something that outside of this framework is basically violence, it's important that you make agreements ... BDSM has a lot of rules: both the general ground rules saying that it has to be safe, sane, and consensual, and ... the personal preferences - your own boundaries. If you're to benefit from pushing your boundaries - something that many people take pleasure in - you have to do it based on mutual trust and communication.

Tina points to a fundamental dilemma in BDSM: between control obtained through the establishment of general rules (SSC) and personal boundaries and the willingness to push these boundaries. This situation is a matter of finding the right balance between taking precautions and taking risks; for many people, the element of risk seems to be precisely what makes BDSM more interesting than 'vanilla' sex. Consent in this context is a way of solving this dilemma. Consent then operates at different levels: as part of the negotiation of rules and boundaries in each situation and in the negotiated willingness to engage with a particular partner (or with BDSM play in general).

Although both Tina and Emma preferred domination to submission, Tina agreed to let Emma teach her how to become a proper dominant through the submissive role. Emma suggested that they discuss sexual preferences and boundaries in writing 'so that we both know what we want', she said. During the first few months, Tina and Emma mostly engaged in physical and sexual BDSM play and spent time working out compromises so that both would benefit. After a few months, Tina agreed to try more extensive psychological dominance during her everyday life. In the beginning, Tina found these more boundless and fluid mental aspects of BDSM exciting. As Emma's servant, Tina was to address her as 'Mistress' and could not touch her without permission. Emma particularly liked when Tina showed off her bruises and scars as signs of Emma's ownership of her. Other ways for Tina to make Emma happy included wearing 'butt plugs' at work, wetting herself in public, or drinking her own urine as ways of proving her willingness to please her 'domina'. Eventually these tasks, all seemingly common in BDSM, started to make Tina more and more uncomfortable. It became increasingly difficult for her to do her job 
properly or to spend time with her own friends - people whom Emma often told her were a bad influence.

As a dominant, Emma expected Tina to email her a description of her tasks for the coming day every night before going to sleep, including sexual activities. One evening about a year after they had first met, Tina fell asleep on the couch without sending this mandatory email to her mistress. When they met the following day, Emma was 'cold as stone', as Tina describes her, and she horsewhipped Tina. Tina was terrified, as she felt the boundary between play and reality was collapsing and that she had lost control of the situation. As is common in BDSM practice, Tina and Emma had agreed on a safe-word for each to use to revoke their consent if things went too far. Looking back at what happened that particular morning, Tina says:

Of course, I could've used the safe-word, and then she would've stopped. But then again, I was convinced that if I'd said 'red', our relationship would have ended there. She felt that she did all this to me as a favour. Or at least that's what she would've said afterwards.

Shortly after this incident, Tina admitted to herself and to Emma that she had fallen in love with her. Because Emma was unwilling to leave her partner, they decided to end their relationship. During the three years that have passed since that time, they have had no contact other than a few messages on social media. But Tina is convinced that Emma is stalking her through anonymous profiles on social media by sending disturbing messages and vague threats. During the first few months after the breakup, Tina became increasingly confused, anxious and depressed. Suddenly she was afraid to leave her apartment without doing a proper risk analysis: which streets were safe and which social venues would put her at risk of bumping into Emma, or her girlfriend or friends.

\section{Drawing the line through shades of grey}

Even before Tina met Emma, BDSM had become a fundamental trait of her personal and social identity; their relationship was defined within this framework. BDSM is still part of who Tina is and wants to be, and therefore, it is crucial for her to define what happened between her and Emma as 'something else'. The overarching problem in Tina's struggle to make sense of what happened to her appears to be the disparity between black-and-white BDSM ideals and the grey areas of actual practice. This situation has led Tina into a constant dichotomisation between legitimate BDSM and illegitimate sexual violence. The BDSM play that she was part of - at least from her own understanding in retrospect - did not feel safe, sane and consensual and therefore could not have been BDSM. But beyond BDSM, Tina has difficulty finding the right words to describe what happened. Was this violence? If so, was the violence physical, sexual or psychological? At what time did the violence start, and is it in fact still going on? 
At the time of the first interview, Tina seemed to have made up her mind, more or less: she claimed to have been exposed to violence by intent in an intimate relationship. It was the consequences of what had happened - the anxiety and depression she had suffered in the period after the relationship ended that made Tina question Emma's moral character and intentions:

I've realised since then that she never did this for me. All that talk about teaching me ... I think she did it to put me in a situation where she could take advantage of me. Where she was allowed... allowed to hit me.

The idea of Emma exploiting the BDSM framework for her own purposes was not helpful for Tina, as she still had to live with her own 'consent' to the actions whose aftermath later caused her so much pain. Using a safe-word essentially means revoking one's consent, and she never used it; she never said 'red'. In Tina's story, consent was a state of mind and was the constant as her initial BDSM experiences over time turned into experiences of sexual violence. The burning question in her story that she constantly returned to was: 'How could I have put myself in such a situation?' She repeatedly accepted and normalised Emma's dominance out of love or fear, constantly pushing her own boundaries until they no longer existed. What exactly does consent mean under such circumstances?

\section{Consent and responsibility}

While power and domination are central aspects of all social relations (Foucault, 1984 [2001]), we may understand violence as a particular kind of power and domination where legitimacy is contested. As Riches notes (1986, p. 10):

the main ambiguities, and therefore misunderstandings, will certainly come from people's inability always to spot acts of hurt which are primarily meant as playful or ritualized, as opposed to those which are directly serious in intent'.

During the interview with several friends from a BDSM club, they debated the question of legitimacy related to intent in relation to the anonymised version of Tina's story.

Just as in my conversations with Tina, the discussion in the group interview was coloured by the participants' insistence on responsibility related to the issue of consent in the story. One of them, a male dominant, described the relationship in the story presented as 'clearly abusive', and claimed that he would never let his sub consent to play on such premises. He particularly questioned Emma's apparent lack of interest in checking in on Tina, ensuring that she was ok emotionally. In his view, Emma had been responsible for creating a coercive context in which free consent had become impossible. Because safe BDSM does not actually exist, this man argued, all participants - and the dominant in particular - must take the issue of risk seriously to avoid people getting hurt. 
Another participant, a submissive male, disagreed with his friend; he claimed that Tina herself had been responsible for this situation and referred to it as 'self-abuse, plain and simple'. As a fellow sub, he insisted on Tina's responsibility for protecting her own boundaries and integrity during BDSM play. Whenever she found that she was unable to do so - for instance because she had unintentionally fallen in love with her mistress - he felt that she should have stopped practising.

The question that all the informants in their different ways tried to answer was one that I never asked them myself: Whose responsibility is it when someone consents to unwanted BDSM play? This is not an issue that can easily be agreed upon based on BDSM moral codes alone. In general, the informants seemed fairly ambiguous when talking about the risks related to BDSM: they drew strict lines between BDSM and sexual violence based on the general SSC guidelines while also engaging in a nuanced problematisation of the same distinctions. They also explained that fellow BDSMers frequently talk about their practice in terms of violence; they even claimed that BDSM is indeed a form of violence. They all seemed to understand the practice of BDSM as 'playing with fire', where the risk of harm is inevitable. They explicitly shared my understanding of risk assessment and safety precautions in BDSM as being more often aimed at physical rather than mental aspects. They explained that, because of the stigmatisation from outside BDSM as a former psychiatric diagnosis, psychological troubles related to the practice tend to become taboo on the inside.

\section{Conclusion: fetishising consent to manage stigma?}

In conclusion, based on the above discussion, Tina's difficult situation is not only related to what happened between her and Emma but also to the general social context and the internal and external mechanism of the stigmatisation of a sexual minority. The social construction of sexual violence in the context of BDSM somehow turns 'abusive BDSM' into an anomaly (Douglas, 1984): a phenomenon that falls between cultural categories and is a potential threat to the social order. Tina's story represents such a threat, both to her and to her fellow BDSMers, since she claims to have been exposed to BDSM as 'consensual violence'.

West addresses the phenomenon of consensual sexual harm: 'at most, the consensuality of the transaction implies only that if the transaction is harmful, or bad, it is so for reasons other than the harmful consequences that flow from the exercise of coercion or force' (2009, p. 20). Because consent has never been a good proxy for well-being, West argues, we should not treat it as such. We should indeed 'quit fetishising consent' (2008, p. 15), she points out, when exploring the frontiers of sex and violence within academic discourse.

The verb 'to fetishise' has two meanings. First, it refers to making something the object of a sexual fetish; second, it refers to having an excessive and irrational commitment to something. During the process of analysing BDSM as ideal and practice, I have come to think of consent as something that could easily be fetishised in the latter sense within this distinct subculture in which sexual fetishism is 
encouraged. I find that people's commitment to consent in BDSM communities might cause serious blind spots concerning their common responsibility in preventing BDSM play from becoming abusive. According to the above-mentioned shift in sexual violence prevention discourse, this fetishising of consent within BDSM seems to be part of a much larger trend in societies and political fields where individualist ideologies dominate, to the point that they are taken for granted. Within such logics, because of the insistence on personal responsibility, the individual tends to be held responsible for consenting to unwanted sex.

Because of the risk related to the potentially coercive circumstances of BDSM, the necessity for nuanced ethical negotiation in practice - particularly in relation to consent - is perhaps more urgent than elsewhere. This study has shown that BDSM as a subculture is indeed characterised by particularly sophisticated ethical negotiations over issues concerning sexual practices and consent: likely much more so than in mainstream sexual practice. People who practise BDSM as part of a community appear to be aware of the risk and social responsibility involved; the widely accepted ground rules - safe, sane and consensual - are precisely meant to prevent people from turning pleasure into abuse. Alongside the rather problematic fetishising of consent, I sense a cultivation of skilful risk management for the benefit of both the group and the individual. The political and academic field of sexual violence might find the potential for several new insights within this universe of rigid obedience to rules alongside the simultaneous pursuit of creative flexibility.

\section{Acknowledgements}

This study was conducted at the Norwegian Centre for Violence and Traumatic Stress Studies and funded by the Norwegian Ministry of Justice and Public Security. The author would like to extend a warm thanks to Yngvil Grøvdal for allowing this little detour from the main research project, and to Ingvild Bergom Lunde for leading the way. Thanks also to informants in the BDSM community for opening doors and giving valuable comments on an early draft, and to the editors for their important contributions towards this final version.

\section{References}

Barker, M. (2013). Consent is a grey area? A comparison of understandings of consent in Fifty Shades of Grey and on the BDSM blogosphere. Sexualities, 16(8), 896-914. doi: $10.1177 / 1363460713508881$

Beres, M. A. (2014). Rethinking the concept of consent for anti-sexual violence activism and education. Feminism \& Psychology, 24(3), 373-389. doi:10.1177/0959353514539652

Cahill, A. J. (2001). Rethinking rape. Ithaca, NY: Cornell University Press.

Carlström, C. (2017). Gender equal BDSM practice: A Swedish paradox? Psychology \& Sexuality, 8(4), 268-279. doi:10.1080/19419899.2017.1383302

Carlström, C. (2018). BDSM - The antithesis of good Swedish sex? Sexualities, 0(0), 1-18. doi: $10.1177 / 1363460718769648$ 
Carmody, M. (2003). Sexual ethics and violence prevention. Social \& Legal Studies, 12(2), 199-216. doi:10.1177/0964663903012002003

Conly, S. (2004). Seduction, rape, and coercion. Ethics, 115(1), 96-121. doi:10.1086/421981

Cross, P. A., \& Matheson, K. (2006). Understanding sadomasochism: An empirical examination of four perspectives. Journal of Homosexuality, 50(2-3), 133-166. doi:10.1300/ J082v50n02_07

Deller, R. A., Harman, S., \& Jones, B. (2013). Introduction to the special issue: Reading the Fifty Shades 'phenomenon'. Sexualities, 16(8), 859-863. doi:10.1177/1363460713508899

Douglas, M. (1984). Purity and danger: An analysis of the concepts of pollution and taboo. London: Ark Paperbacks.

Fanghanel, A. (2019). Asking for it: BDSM sexual practice and the trouble of consent. Sexualities, 0(0), 1-18. doi:10.1177/1363460719828933

Foucault, M. (1984). The history of sexuality 1: An introduction (Vol. 1). Harmondsworth, UK: Penguin.

Foucault, M. (1984 [2001]). L'ethique du souci de soi comme pratique de la liberte. In D. Defert \& F. Ewald (Eds.), Dits et écrits II, 1976-1988 (pp. 1527-1548). Paris: Quarto Gillimard.

Foucault, M. (1985 [2014]). Morality and practice of the self. In D. Fassin \& S. Leze (Eds.), Moral anthropology: A critical reader (pp. 41-45). New York: Routledge.

Foucault, M. (2001). In D. Defert \& F. Ewald (Eds.) Dits et écrits, 1954-1988. Paris: Gallimard.

Foucault, M. (2003). 'Society must be defended': Lectures at the Collège de France, 1975-76. New York: Picador.

Foucault, M. (2009). Security, territory, population: Lectures at the Collège de France, 1977-78. In M. Senellart, F. Ewald, A. Fontana, \& G. Burchell (Eds.), Michel Foucault: Lectures at the College de France. New York: Picador.

Gavey, N. (2005). Just sex? The cultural scaffolding of rape. London: Routledge.

Gunnarsson, L. (2018). 'Excuse me, but are you raping me now?' Discourse and experience in (the grey areas of) sexual violence. Nora: Nordic Journal of Feminist and Gender Research, 26(1), 1-15.

Hickman, S. E., \& Muehlenhard, C. L. (1999). 'By the semi-mystical appearance of a condom': How young women and men communicate sexual consent in heterosexual situations. Journal of Sex Research, 36(3), 258-272.

Larcombe, W., Fileborn, B., Powell, A., Hanley, N., \& Henry, N. (2016). 'I think it's rape and I think he would be found not guilty': Focus group perceptions of (un)reasonable belief in consent in rape law. Social \& Legal Studies, 25(5), 611-629.

Martin, R. (2011). Powerful exchanges: Ritual and subjectivity in Berlin's BDSM scene. ProQuest Dissertations Publishing. https://dataspace.princeton.edu/jspui/handle/88435/ dsp01qz20ss51g

McClintock, A. (1993). Maid to order: Commercial fetishism and gender power. Social Text, 37, 87-116. doi:10.2307/466262

Newmahr, S. (2010). Power struggles: Pain and authenticity in SM play. Symbolic Interaction, 33(3), 389-411. doi:10.1525/si.2010.33.3.389

Newmahr, S. (2011). Playing on the edge: Sadomasochism, risk, and intimacy. Bloomington: Indiana University Press.

Pateman, C. (1980). Women and consent. Political Theory, 8(2), 149-168. doi:10.1177/ 009059178000800202

Reed, G. M., Drescher, J., Krueger, R. B., Atalla, E., Cochran, S. D., First, M. B., ... Saxena, S. (2016). Disorders related to sexuality and gender identity in the ICD-11: 


\section{Monika Grønli Rosten}

Revising the ICD-10 classification based on current scientific evidence, best clinical practices, and human rights considerations. World Psychiatry, 15(3), 205-221. doi:10.1002/ wps. 20354

Riches, D. (1986). The phenomenon of violence. In D. Riches (Ed.), The anthropology of violence (pp. 1-27). Oxford, UK: Blackwell.

Rubin, G. S. (1984). Thinking sex: Notes for a radical theory of the politics of sexuality. In C. Vance (Ed.), Pleasure and danger: Exploring female sexuality (pp. 267-319). Pandora: London.

Smart, C. (1995). Law, crime and sexuality. London: Sage.

Timmermans, S., \& Tavory, I. (2012). Theory construction in qualitative research. Sociological Theory, 30(3), 167-186. doi:10.1177/0735275112457914

Weinberg, T. S. (2006). Sadomasochism and the social sciences: A review of the sociological and social psychological literature. Journal of Homosexuality, 50(2-3), 17-40. doi:10.1300/J082v50n02_02

West, R. (2008). Sex, law and consent. Faculty Working Paper, Georgetown University Law Center. https://scholarship.law.georgetown.edu/cgi/viewcontent.cgi?referer=https:// www.google.com/\&httpsredir=1\&article=1073\&context=fwps_papers

Wiseman, J. (1996). SM 101: A realistic introduction. San Francisco: Greenery Press.

World Health Organization (WHO). (2002). World report of violence and health. Geneva: WHO. 